\title{
PerCursos
}

\section{O desastre da talidomida na Espanha: usos da memória em busca por reparação}

\section{Resumo}

A teratogenia (anomalia que acomete o embrião ou feto) provocada em bebês por conta da ingestão do medicamento talidomida por mulheres grávidas é considerado pela comunidade científica um dos maiores desastres gerados por fármacos durante o século XX. Fabricada por uma empresa farmacêutica alemã, a Grünenthal, a droga foi comercializada em mais de quarenta países a partir do final da década de 1950, afetando milhares de crianças. Na Espanha, o desastre da talidomida foi assunto na mídia impressa a partir de 1962, ocupando espaço até os dias atuais, sobretudo por conta das ações da Associação das Vítimas da Talidomida da Espanha (AVITE). Tendo como fundamento teórico a História do Tempo Presente e a História Oral, esse ensaio se propôs a analisar especificamente uma série de entrevistas de vítimas da droga farmacêutica, buscando problematizar questões relativas à memória e os usos que são feitos dela. A análise dessa amostra de fontes proporcionou uma visão ampliada acerca da representação do desastre e da luta por reparação realizada pelos afetados e comprovou a relevância da História Oral na composição adensada de uma história da talidomida na Espanha.

Palavras-chave: Talidomida. Memória. Reparação. Espanha. AVITE.

\author{
Dones Cláudio Janz Júnior \\ Mestre em História pela \\ Universidade Federal do Paraná - \\ UFPR. Doutorando em História \\ na Universidade do Estado de \\ Santa Catarina - UDESC. \\ Professor da Univ. Estadual de \\ Ponta Grossa - UEPG. \\ Brasil \\ donesjr@hotmail.com
}

\footnotetext{
Para citar este artigo:

JANZ JÚNIOR, Dones Cláudio. O desastre da talidomida na Espanha: usos da memória em busca por reparação. Revista PerCursos, Florianópolis, v. 20, n.42, p. 08 - 28, jan./abr. 2019.
}

DOI: $10.5965 / 1984724620422019008$

http://dx.doi.org/10.5965/1984724620422019008 


\title{
The disaster of talidomida in Spain: uses of the memory in search for repair
}

\begin{abstract}
Teratogenicity (anomaly that affects the embryo or fetus) in infants due to ingestion of the drug thalidomide by pregnant women is considered, by the global scientific community, one of the largest druginduced disasters during the twentieth century. Manufactured by a German pharmaceutical company, Grünenthal, the drug was commercialized in more than forty countries from the late 1950s, affecting thousands of children. In Spain, the thalidomide disaster was a matter in the print media from 1962 on, taking up space to this day, mainly because of the actions of the Association of Victims of Thalidomide of Spain (AVITE). Based on the theoretical basis of the History of Present Time and Oral History, this essay set out to analyze specifically a series of interviews of victims of the pharmaceutical drug, seeking to problematize issues related to memory and the uses that are made of it. The analysis of this sample of sources provided an expanded view of the representation of the disaster and the struggle for reparation carried out by AVITE.
\end{abstract}

Keywords: Thalidomide. Memory. Repair. Spain. AVITE. 


\section{Introdução}

O ponto de partida que fomenta essa reflexão ocorreu durante o ano de 2013, quando um juiz da Espanha condenou, pela primeira vez na história, a empresa farmacêutica alemã Chemie Grünenthal a compensar as vítimas reconhecidas pelo Estado espanhol da "tragédia da talidomida", evento ocorrido entre as décadas de 1950 e 1960. A companhia interpôs recurso ao Tribunal Provincial de Madrid, anulando a condenação no final de 2014, fazendo com que as disputas acerca da questão ainda aconteçam.

A continuidade desse processo e, sobretudo, a presença de testemunhos do passado que possam fornecer seus relatos como fontes históricas, o torna substrato para um estudo a partir da proposta de uma História do Tempo Presente (HTP), modalidade historiográfica que alvitra estudar uma história inacabada ou, nas palavras de Bédarida, "uma história em constante movimento, refletindo as comoções que se desenrolam diante de nós" (BÉDARIDA, 1996, p. 229).

Temas como memória, justiça e reparação são fundamentais na atualidade e o processo em curso concernente à comercialização e à ingestão da talidomida na Espanha envolve cabalmente esses pontos. Temos um cenário no qual a memória das vítimas é peça importante para a montagem do quebra-cabeça acerca do desastre ocorrido durante as décadas de 1950 e 1960 e seus desdobramentos. Soma-se a isso o fato de que o processo é fruto de busca por reparação e justiça, situação que engloba o Estado espanhol e a indústria farmacêutica.

Não obstante, entende-se que os historiadores podem contribuir nesse processo ao dar subsídios - levantando dados e os problematizando, anotando e analisando vozes e versões, revelando situações não conhecidas - para fomentar o debate do assunto, levando em conta as demandas sociais do momento.

A correlação entre esses assuntos está intimamente ligada com a própria prática de uma História do Tempo Presente, tal qual indica Christian Delacroix (2018). Segundo ele, os processos de institucionalização da HTP são, em grande maioria, frutos de demandas sociais por reparação e justiça relativos a passados traumáticos, chamados pelo historiador francês de "reivindicações memoriais". 
Envolvida na disputa pelo reconhecimento e indenização das vítimas das deformações provocadas pela ingestão do fármaco, está a Associação das Vítimas da Talidomida na Espanha (AVITE), organização criada em março de 2004, a qual impetrou uma ação contra a Grünenthal, solicitando sua responsabilização pelas malformações nos recém-nascidos e o ressarcimento pelos danos provocados. Além da esfera jurídica, a AVITE atua por meio de outras práticas, dentre elas, a manutenção de um sítio de internet no qual disponibiliza uma série de documentos, notas de imprensa, coberturas do debate na mídia e vídeos com relatos de vítimas do fármaco.

Ancorado nesse processo, o seguinte texto procura apresentar algumas reflexões sobre o uso de relatos orais e da memória das vítimas feitas pela AVITE em sua página digital'. Dentre as várias fontes disponíveis, esse texto se debruça sobre uma série audiovisual intitulada “Mesa Redonda de AVITE”, na qual quatro afetados pela talidomida são entrevistados pela escritora Rosario Raro. Tal material foi escolhido por apresentar uma série coerente de entrevistas com vítimas que conhecem e participam da luta judicial pela responsabilização da Grünenthal.

Em pesquisas que envolvem reinvindicações memoriais, a História Oral é uma opção privilegiada por, primeiramente, permitir que pessoas tradicionalmente excluídas sejam ouvidas e que suas versões sejam interpretadas como fontes históricas. Os afetados pela talidomida historicamente foram negligenciados e as fontes que se apresentam, como os jornais da época, não são suficientes para fornecer dados que permitam uma visão mais aprofundada das consequências da teratogenia medicamentosa. A isso, soma-se o fato de que entendemos que a história oral nos dá novas possibilidades de análise, distintas daquelas fornecidas habitualmente dentro do rigor acadêmico.

Seligmann-Silva (2012, p. 103), ao tratar da relevância de testemunhos em casos de traumas sociais, assevera que é "uma tentativa de se escovar a história a contrapelo,

\footnotetext{
${ }^{1}$ Neste artigo, utilizamos exclusivamente dados de domínio público de acesso irrestrito. Entretanto, como essa análise é um desdobramento de pesquisa de maior vulto referente ao doutoramento, informamos que a mesma conta com submissão ao Comitê de Ética em Pesquisas Envolvendo Seres Humanos da Universidade do Estado de Santa Catarina - CEPSH/UDESC.
} 
abrindo espaço para aquilo que normalmente permanece esquecido, recalcado e legado a um segundo (ou último) plano".

Além disso, inúmeras são as possibilidades ofertadas pela memória, aos estudos históricos. A memória, “como forma de conhecimento e como experiência, é um caminho possível para que sujeitos percorram a temporalidade de suas vidas", segundo Delgado (2003). Tal característica insere a memória como ferramenta crucial para a construção do conhecimento histórico, permitindo-nos pensar sobre a construção das identidades das vítimas ou mesmo sobre as suas representações sobre o passado.

Outro fator relevante que endossa nossa opção diz respeito à relevância da História Oral para a reflexão da História do Tempo Presente. Marieta Ferreira (2002) vai apresentá-la como uma bússola que nos motiva a enfrentar os problemas na construção do conhecimento histórico.

Sendo assim, a questão que nos impele nessa reflexão é: como os relatos orais das vítimas contribuem para a elaboração de uma história do desastre na Espanha e suas repercussões sociais atuais? Tal análise objetiva refletir sobre os usos da memória das vítimas feitos pela AVITE, tentando com isso pensar sobre como se estruturam suas estratégias de busca por reparação e justiça. Tomando a memória como algo condicionado pelo presente, que muda de conteúdo a partir das demandas e circunstâncias atuais, utilizaremos das bases teórico-metodológicas da História Oral aliadas a outras fontes documentais para a melhor compreensão sobre a história acerca do desastre provocado pela talidomida na Espanha.

\section{A talidomida na Espanha}

A talidomida, fármaco vendido no final da década de 1950 como indutor do sono e para aliviar as náuseas causadas pela gravidez, foi responsável por um dos maiores desastres relacionados ao uso de medicamentos do século XX: o nascimento de milhares de bebês com deformidades congênitas. Produzida pela empresa farmacêutica Chemie Grünenthal, da Alemanha Ocidental, alcançou grande sucesso a partir de 1957, sendo comercializada, em 1959, em 48 países da Europa e África, assim como no Japão, Austrália 
e Canadá, alcançando depois outros países da América do Sul, especialmente o Brasil (MARTÍNEZ-FRÍAS, 2012, p. 26).

Esse medicamento foi inicialmente vendido sem necessidade de prescrição médica, pois a Grünenthal afirmava que ele era "inteiramente atóxico". No final de 1961, entretanto, "ficaram evidentes os resultados clínicos de que a droga era a responsável pela epidemia do nascimento de milhares de bebês, em várias partes do mundo, especialmente na Europa, com diversos sinais teratológicos" (LEANDRO; LOPES, 2013, p. 4).

Tonturas e neuropatia periférica foram efeitos adversos observados entre os que ingeriram o produto e, posteriormente, comprovou-se que a focomelia ${ }^{2}$ em recém-nascidos era fruto da iatrogenia ${ }^{3}$ medicamentosa. Efeitos colaterais apareceram em milhares de crianças, chamadas de "bebês da talidomida", porque suas mães, nos meses iniciais de gestação, ingeriram a droga, sobretudo, para alívio do desconforto dos enjoos matinais. (LEANDRO E SANTOS, 2015, p. 994)

Com a confirmação de sua toxicidade, a talidomida foi retirada do mercado mundial a partir de dezembro de 1961 (MORO; INVERNIZZI, 2017, p. 607). Na Espanha, entretanto, documentos disponíveis no site da AVITE 4 demonstram propaganda da marca SOFTENÓN, datada de dezembro de 1961 (figura 1). A retirada de marcas como o ENTEROSEDIV, que também continha talidomida na sua fórmula química, foi efetivada apenas a partir de setembro de 1962.

\footnotetext{
${ }^{2}$ Atrofia ou ausência de braços e pernas, ficando pés e mãos ligados diretamente ao tronco, à semelhança das nadadeiras das focas.

${ }^{3}$ Doença com complicações causadas como resultado de um tratamento médico.

${ }^{4}$ Disponível em: <http://www.avite.org/documentos/> Acesso em: 16 abr. 2018.
} 
Figura 1 - propaganda farmacêutica que apresenta o medicamento SOFTENÓN, publicada em dezembro de 1961

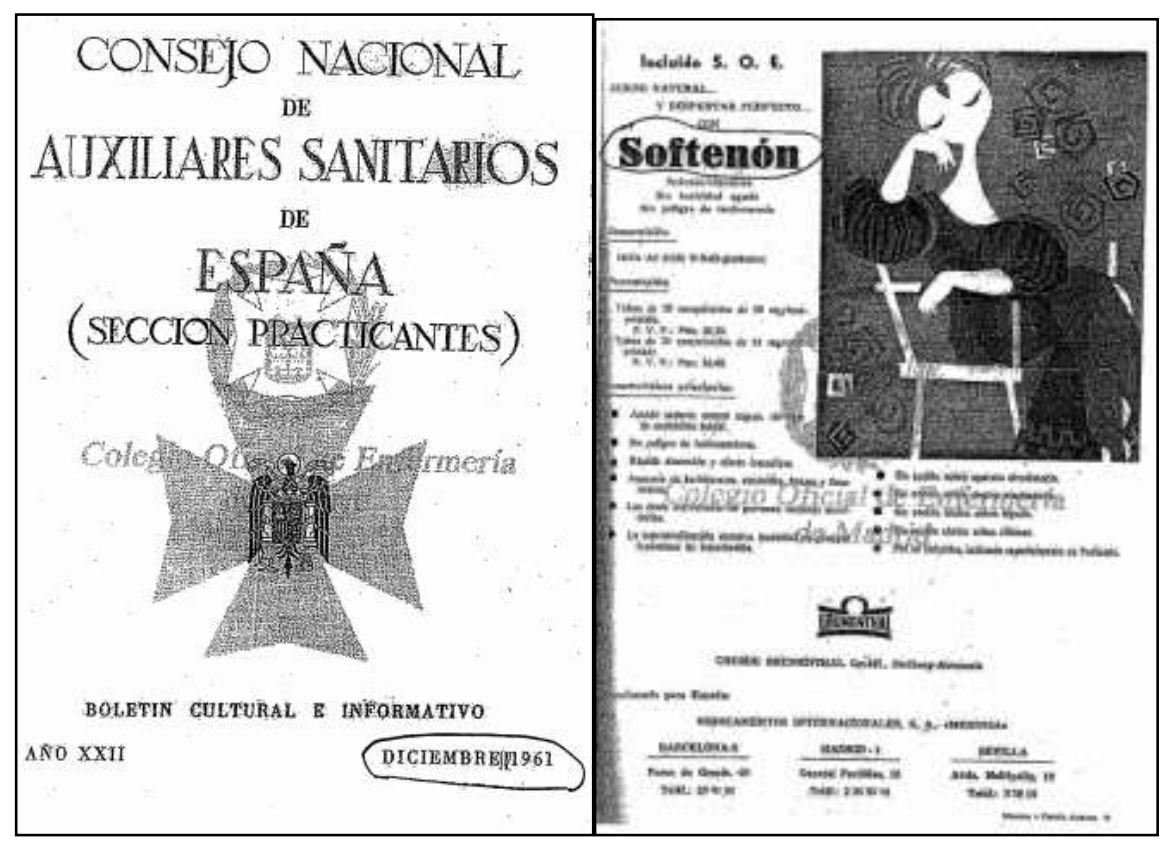

Fonte: http://www.avite.org/propaganda-del-softenon-con-talidomida-de-grunenthal-en-espanaen-diciembre-de-1961-en-la-revista-auxiliares-sanitarios/

A AVITE iniciou sua mobilização em busca da responsabilização da Grünenthal em 2004, num contexto político favorável relacionado à chegada ao poder, em março daquele ano, do Partido Socialista Operário Espanhol, o que tornou José Luis Rodríguez Zapatero o presidente da Espanha. Uma pauta progressista foi implementada - o primeiro executivo conjunto entre homens e mulheres na história, a Lei contra a Violência de Gênero, a Lei da Igualdade, a Lei da Memória Histórica e a Lei que possibilitava o casamento a pessoas do mesmo sexo - e, com ela, uma expectativa de valorização de vozes anteriormente silenciadas. Desde então, a AVITE se mobiliza para requerer a responsabilização e o pagamento de indenizações por parte da indústria alemã como medida de reparação pelos efeitos físicos e psicológicos causados pelas malformações congênitas.

A partir dos anos 2010, com o pagamento de compensações para algumas das vítimas do desastre medicamentoso por parte do governo espanhol ${ }^{5}$ e a investida da

\footnotetext{
5 O Governo espanhol promoveu um pacote extraordinário de medidas para prestar ajuda às pessoas
} 
Associação de Vítimas da Talidomida na Espanha (AVITE) para o ressarcimento dos afetados pela Grünenthal, a talidomida tornou-se novamente um assunto de grande repercussão. O jornal El País, por exemplo, possui um site ${ }^{6}$ exclusivo sobre assuntos ligados à talidomida, o que demonstra a grande capilaridade do assunto na sociedade espanhola atualmente.

\section{Usos da memória e luta por reparação}

A análise das fontes na página da associação demonstra que existe uma tentativa de formatação de uma memória atual atrelada ao descaso e sofrimento vividos pelas vítimas desde a década de 1960. A partir de documentos variados, testemunhos e produções próprias, a AVITE busca elaborar uma narrativa que sensibilize o público em busca de apoio à luta por reparação.

Reportagens com documentos que comprovam situações silenciadas pela grande mídia chamam a atenção. Sob o título Recetas de Talidomida en España en los años 1976, 1977 y 1978, por exemplo, são apresentados diversos receituários médicos que supostamente comprovariam o uso da droga mesmo depois de sua proibição. Em outra página, observamos a afirmação de que a Grünenthal sabia da venda desenfreada do medicamento a despeito da advertência de que ele era potencialmente teratogênico.

Essa diversidade de fontes (literatura médica, depoimentos, programas televisivos sobre a tragédia produzidos em outros países, notícias, receituários médicos, obras científicas e literárias, patentes, vídeos publicitários), que pode ser verificada na figura 2, indica claro posicionamento da associação na busca pela ocupação de espaços públicos.

afetadas. Apenas 24 conseguiram obtê-lo, conforme estabelecido no Artigo 2 do Real Decreto 1006/2010. As ajudas previstas variam entre 30.000 euros para uma deficiência demonstrada entre 33 e 44 por cento e 100.000 euros para aqueles com um grau de incapacidade de $75 \%$ ou superior. O prazo para o pedido de ajuda expirou em 30 de setembro de 2010 e devia ser justificado por um documento de acreditação da deficiência emitido pelo Instituto de Saúde Carlos III, do Ministério da Saúde.

${ }^{6}$ Disponível em: <http://elpais.com/tag/caso_talidomida/>. Acesso em 16 abr. 2018. 
Figura 2 - página "Hemeroteca" do site da AVITE apresenta mais de duas mil fontes para consulta acerca do assunto

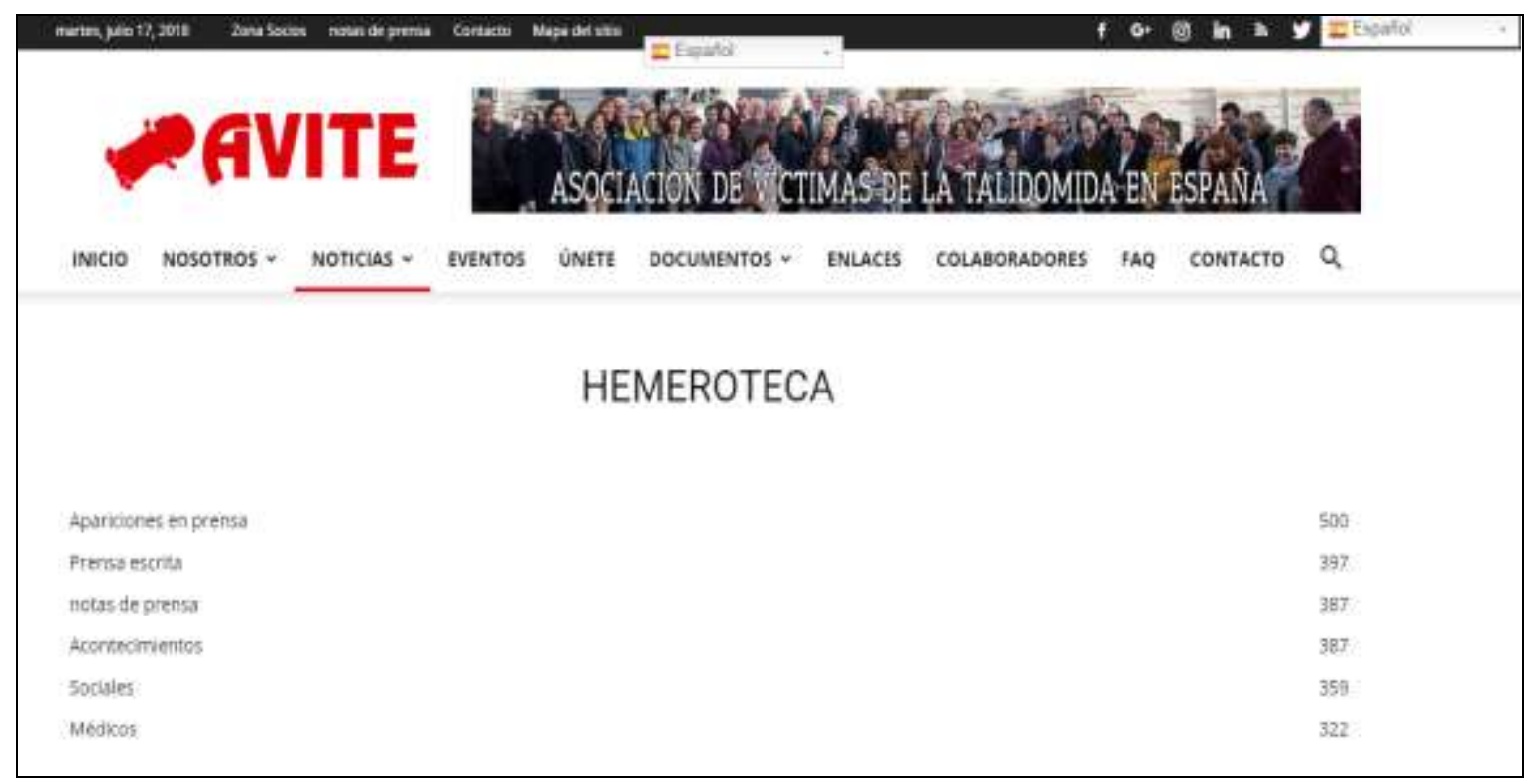

Fonte: http://www.avite.org/.

Verifica-se uma iniciativa de elaborar uma história feita pelo público não acadêmico, mas que se orienta por uma legitimação acadêmica. Partindo dessa estratégia, a AVITE procura reforçar uma memória negativada acerca da Grünenthal (documentos que atestam a ciência dos efeitos pela empresa, relação com o nazismo etc.) com o objetivo de fortalecer a sua luta por reparação.

Para esse trabalho, nossa ênfase recai, como anteriormente mencionado, sobre uma série de relatos audiovisuais disponíveis na página da AVITE, produzidos em 2016 . São seis episódios com cerca de onze minutos cada, nos quais diferentes abordagens acerca da luta por justiça e a condição de vida das vítimas é abordada pela escritora espanhola Rosario Raro. Rosario apoia publicamente a luta da AVITE por meio de entrevistas e eventos nos quais dedica parte de seus lucros com a venda de livros à associação.

Os episódios são fruto de uma entrevista realizada em 08 de junho de 2016, na cidade de Murcia. Segundo a própria AVITE, foi uma iniciativa para denunciar as 7 Disponíveis em: <https://www.youtube.com/channel/UCDnZvpih-uJVWKMoguzcjzw>. Acesso em: 20 abr.
2018. 
dificuldades enfrentadas pelas vítimas no mesmo momento em que o presidente da associação, Jose Riquelme, foi homenageado na cidade por conta de suas ações em busca dos direitos dos afetados pela talidomida.

Nesse material, observa-se uma roda de conversas em que quatro vítimas do fármaco (Pepe, Mariano, Rafa e Ana) são questionadas sobre suas experiências de vida relacionadas às deficiências físicas causadas pela droga, bem como acerca da situação daquele momento da disputa judicial contra a Grünenthal.

Já no início do vídeo, ao ser perguntado sobre sua avaliação do atual momento, Pepe, fundador e atual presidente da AVITE, demonstra-se apreensivo com a falta de resultados que beneficiem as vítimas: "O sentimento é de decepção, mostra-nos o poder

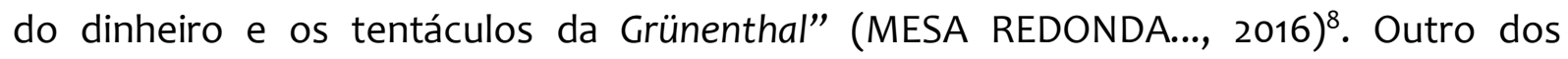
entrevistados, Rafa (Rafael Basterrechea, atual vice-presidente da AVITE), também se mostra decepcionado, ao comentar a máxima "a ética não deveria prescrever", invocada pela entrevistadora: "a ética parece importar pouco e os interesses comerciais sobressaem" (MESA REDONDA..., 2016).

No contexto em que o material foi produzido, a Justiça Espanhola havia negado a indenização aos afetados, com o argumento de que o caso da talidomida havia prescrito. A sentença, proferida em 23/09/2015, foi assim noticiada pelo jornal El Pais:

El Supremo ha confirmado así la sentencia del año pasado de la Audiencia Provincial de Madrid, que desestimó la demanda de responsabilidad civil contra Grünenthal al entender que estaba prescrito. El argumento se basa a que la ingesta de las mujeres del fármaco se produjo a finales de los cincuenta y principios de los sesenta del siglo pasado, aunque los afectados alegan que no hubo reconocimiento oficial de sus lesiones y su causa hasta 2010, por lo que no pudieron emprender acciones antes (RINCÓN; DE BENITO, 2015).

O Tribunal alegou que os danos provocados pela talidomida eram agravos permanentes e que, para as alegações de responsabilização da farmacêutica alemã serem

\footnotetext{
${ }^{8}$ Optamos pela tradução livre para o português dos relatos orais analisados nesse texto.
} 
aceitas, as vítimas deveriam ter acionado a justiça no prazo máximo de um ano após terem atingido a maioridade. Fica claro, nesses trechos, que a insatisfação dos afetados se expressa de maneira a vincular a não aceitação de suas solicitações ao poder econômico da farmacêutica alemã. Ao relacionar a sentença à falta de ética e ao poder econômico, ambos os relatos optam por ligar a derrota no tribunal a forças externas que estariam agindo sobre as decisões judiciais. Indícios que fundamentem esse posicionamento ainda precisam ser encontrados, contudo, o poder econômico da Grünenthal, uma das grandes empresas do setor farmacêutico nos últimos sessenta anos, não pode ser ignorado9 .

Em outro momento da entrevista, Raro os questiona sobre suas condições de vida e lembranças da infância e adolescência, permitindo a eles que demonstrassem como se sentiam frente aos olhares dos outros. A memória do tema é assim relatada por Rafa: “Quando criança, eu percebia o olhar dos outros positivamente, me sentia um atrativo. Já o momento mais cruel foi aos dezesseis/dezessete anos quando os pais de minha namorada a proibiram de me namorar por não acreditarem que eu poderia the oferecer alguma perspectiva de futuro" (MESA REDONDA..., 2016). Ana, vítima do medicamento e associada da AVITE, respondeu que o seu "lema sempre foi: viva e não deixe que nada lhe impeça", o que demonstra uma postura de enfrentamento da situação. Contudo, em sua memória, também é nítida a lembrança de quando tinha quatro ou cinco anos de idade e ao conversar com sua mãe, solicitou: “quero um braço”. Fato relevante é a sua afirmação seguinte: "Soube há apenas três anos que, por ganância comercial, não tenho os meus membros" (MESA REDONDA..., 2016).

As edições de 4 e 5 de janeiro de 1963 do periódico Hoja del Lunes, por exemplo, trouxeram uma minuciosa reportagem intitulada Yo acuso - La verdade acerca de la talidomida sobre a descoberta da toxicidade da droga pelo médico alemão W. Lenz.

\footnotetext{
9 Dados retirados do site da empresa confirmam essa afirmação: "A Grünenthal é uma empresa farmacêutica internacional de investigação, familiar e independente, com sede em Aachen. Está representada em 30 países com filiais na Europa, América Latina e Estados Unidos da América. Os seus produtos são vendidos em mais de 100 países e trabalham, no Grupo Grünenthal em todo o mundo, aproximadamente 5.200 colaboradores. Em 2017, a Grünenthal obteve receitas no valor aproximado de 1.3 mil milhões de euros". Fonte: <https:/www.grunenthal.pt/grtweb/Grunenthal_Portugal/Empresa/pt_PT/154101155.jsp>. Acesso em: 30 jun. 2019.
} 
Entretanto, apesar da repercussão sobre os casos de focomelia nos jornais espanhóis, entre 1962 e 1963, parece que, até recentemente, muitos dos afetados realmente não sabiam que sua condição estava atrelada ao uso do medicamento por suas mães.

Essa condição é reiterada por Pepe que, ao retratar como descobriu a causa de sua deficiência física, afirmou: "aos dezessete anos fui fazer um raio-x em minha perna, quando o técnico me questionou: - é causado por talidomida? A partir desse momento, decidi pesquisar o que era esse medicamento e como afetou as pessoas..." (MESA REDONDA..., 2016).

Como afirma Martínez-Frías (2012, p. 28):

En los primeros anõs de la segunda mitad del siglo XX, las causas de las malformaciones congénitas eran desconocidas, cuando no se les atribuían causas esotéricas; además, se cría que la placenta protegía al embrión y al feto de todos los agentes externos.

A mesma autora lembra que apenas com estudos científicos mais recentes foi possível comprovar empiricamente que a talidomida era a responsável por uma série de malformações congênitas específicas. Sendo assim, "sin embargo, es necessário aclarar que en los tiempos del descubrimiento del efecto de la talidomida, y durante varios lustros después, no se podían documentar estos aspectos" (MARTÍNEZ-FRÍAS, 2012, p. 29). Dessa forma, justifica-se a descoberta das causas da síndrome há pouco tempo por alguns dos entrevistados, o que busca embasar e legitimar o processo de fortalecimento da luta por reparação a partir de um passado recente.

Em outro momento, ao abordar questões sobre a família e a sociedade, Ana responde:

Os pais são as primeiras vítimas desse infortúnio, porque para nós demora algum tempo, para eles o sofrimento é desde o nascimento. $O$ médico me mostrou à minha mãe antes de cortar o cordão umbilical para mostrar que não tinha sido ele o responsável (MESA REDONDA..., 2016). 
Rafa aponta que "é uma vida difícil, porque a sociedade é cruel. Você tem que ser o melhor no que faz para compensar a deficiência. Nunca seremos o presidente... temos que lutar e lutar para provar que somos iguais aos outros" (MESA REDONDA..., 2016). Já Pepe relembra:

Entendo minha condição como resultado de uma loteria macabra, uma roleta russa. Me esconderam três dias, após o nascimento, da minha mãe, enrolado em uma fralda. Minha mãe encontrou o médico em certa ocasião e disse a ele que era o culpado por aquilo (MESA REDONDA..., 2016).

O sofrimento das vítimas frente a sua condição física marca esses últimos depoimentos. O pesar pelo enfrentado pelos pais de Ana, o esforço diário e trabalhoso para combater o preconceito social relatado por Rafa, e a oportunidade da responsabilização verbal do médico, por parte da mãe de Pepe, carregam de sentimentos os relatos orais apresentados no vídeo.

As emoções declaradas nos servem como substrato para entender como o processo foi vivido e como elas são refletidas pela memória. Segundo Farge, o sentimento tem "formas, palavras, formas de expressão que têm implicações sociais e políticas e que pertencem plenamente à história" (FARGE, 2011, p. 16). Ela nos instiga a estudar como as palavras de sofrimento relacionadas a um trauma podem ser percebidas como caminhos para adentrarmos o que a autora nomeia como "as moradas vivas da história". Para a autora, perceber e analisar como a dor é sentida ou recusada por uma sociedade é extremamente relevante para pensarmos sobre ela. A partir da afirmação de que "o sofrimento pode tanto repugnar quanto seduzir, gerar modos de assistência, sentimentos de compaixão" (FARGE, 2011, p. 19), essa reflexão contribui para pensarmos como a sociedade espanhola se posicionou frente ao tema ao longo do tempo. A priori, os testemunhos apontam para uma postura preconceituosa e limitante por parte significativa da sociedade espanhola ${ }^{10}$.

\footnotetext{
10 As limitações à vida cotidiana impostas pelas malformações causadas pela talidomida marcaram as histórias dos afetados. Um paralelo possível se dá, com nuances distintas, a condição de vida das vítimas
} 
No caso deste trabalho, seria leviano propor uma análise aprofundada acerca da recepção social dos portadores da síndrome da talidomida pela sociedade espanhola ao longo das últimas décadas, por conta de seu objetivo e brevidade. Entretanto, os depoimentos apontam para uma vida social difícil, com muitos obstáculos vivenciados pelas vítimas, o que se traduz em memórias dolorosas. Também indicam uma postura que busca atingir a sociedade na atualidade, de forma geral, a partir de um discurso fortemente sentimental. Como sabemos, as vítimas, ao reivindicarem o direito à memória, estão dentro de uma disputa de narrativas, nesse caso, balizadas pela busca por direitos não conquistados.

Uma das questões mais instigantes acontece quando Rosario Raro pergunta sobre o que as vítimas pensam acerca da hipótese de que a síntese química da talidomida possa ter ocorrido antes do que se propaga publicamente pela Grünenthal. Tanto Rafa, quanto Pepe levantam a hipótese de que a invenção da droga possui ligação com as experiências alemãs realizadas durante a Segunda Guerra Mundial, vinculando seu sofrimento ao legado nazista. Pepe relata: "procuro provas que relacionem a talidomida aos médicos de Auschwitz" (MESA REDONDA..., 2016).

Dentro da historiografia, há poucos indícios que comprovem essa relação ${ }^{11}$, apesar da conhecida prática de experiências e desenvolvimento de medicamentos ocorridos durante a época da guerra. Contudo, Rafa, que é vice-presidente da AVITE, já mencionou essa tese em outras circunstâncias ${ }^{12}$, o que demonstra uma tentativa de relacionar a talidomida aos horrores praticados nos campos de concentração alemães.

A aproximação do desastre da talidomida ao Holocausto demonstra uma interpretação carregada de presente, na qual a tragédia humana por definição é usada para dar maior visibilidade ao desastre medicamentoso dos anos 1950-1960. Aqui,

da bomba atômica retratadas no capítulo "Depois da catástrofe" da clássica obra de John Hersey Hiroshima. Para saber mais, ler HERSEY, 2002.

${ }^{11}$ Para o historiador argentino Carlos De Napoli, a talidomida foi desenvolvida muito antes da data em que foi oficialmente patenteada, tendo sido testada nos campos de concentração. Sobre o mesmo assunto, o britânico Martyn Johnson aponta que sua investigação fortaleceu a hipótese de que a talidomida era "o último crime dos nazistas". Para saber mais sobre a tese de De Napoli, ler: DE NAPOLI, Carlos. A fórmula da eterna juventude e outros experimentos nazistas. Rio de Janeiro: Civilização Brasileira, 2012.

12 Disponível em: <http://www.rmedica.es/edicion/259/el-germen-nazi-de-la-fabrica-de-la-talidomida $>$. Acesso em: 16 abr. 2018. 
evocamos Andreas Huyssen que, ao discutir os usos do passado, afirma que "os traumas históricos figuram no primeiro plano e no centro da política mundial de memória” (HUYSSEN, 2014, p. 177). Utilizado transnacionalmente como baliza histórica sobre genocídios e, por consequência, como exemplo de trauma, o Holocausto passa a ser usado como parâmetro para outros traumas históricos. A memória desse evento passou a ser incluída em contextos que muito se distanciam no viés político, étnico e cultural. Ao problematizar a questão, Huyssen (2014, p. 187) escreve:

[...] é exatamente a emergência do Holocausto como tropo universal que permite à sua recordação aderir a situações locais específicas, que são historicamente distantes e politicamente distintas do evento original. No movimento transnacional das políticas de memória, o Holocausto perde sua qualidade de índice do evento específico e passa a funcionar como metáfora de outras histórias e lembranças traumáticas.

Tal característica, no entanto, não deslegitima os relatos dados pelas vítimas. Ao refletir sobre o lugar das fontes orais em uma história da memória, Henry Rousso (2006, p. 98) afirma:

[...] um indivíduo, quer fale espontaneamente do seu passado e de sua experiência, que seja interrogado por um historiador, não falará senão do presente, com as palavras de hoje, com uma sensibilidade do momento, tendo em mente tudo o quanto possa saber sobre esse passado que ele pretende recuperar com sinceridade e veracidade. Essa versão é não só legítima, devendo como tal ser reconhecida, como também indispensável para todo historiador do presente.

Evidencia-se assim, o conhecimento acerca do caráter contemporâneo das narrativas coletadas, o que, entretanto, não deslegitima a utilidade das fontes produzidas. Obviamente, cabe ao historiador analisar o depoimento à luz de seus conhecimentos científicos, o que o torna responsável por identificar o que pode ser utilizado e o que precisa ser contraposto com outras fontes, a fim de que componha seu arsenal explicativo. 
Naturalmente, seria precipitado e desonesto generalizar a questão sobre a ligação entre a talidomida, a Grünenthal e o nazismo como simples fruto das políticas cosmopolitas da memória; entretanto, podemos aventar que tais afirmações se encaixam nesse cenário. Entendido por essa chave, concordamos com Huyssen quando afirma que em tempos de globalização, "a memória do sofrimento histórico é vinculada a reivindicações políticas e jurídicas universalistas" (HUYSSEN, 2014, p. 185). As relações apresentadas pelas vítimas conformam-se, assim, em estratégia retórica de valorizar o desastre da talidomida associando-o a uma tragédia quase consensual, legitimando as demandas de reparação.

Selligmann-Silva (2010) discute conceitualmente a noção de testemunho buscando sua relação com a realidade, apresentando-o como instrumento político de manutenção de uma memória contra o esquecimento em casos de traumas sociais. Nesse sentido, os testemunhos utilizados para a publicização da luta por reparação impetrada pela AVITE também possuem o objetivo político de manter o passado vivo no presente, buscando com isso a mobilização e o convencimento em prol da responsabilização da Grünenthal.

Com o argumento de que "[...] los demandantes no han podido aportar las pruebas que justifican sus reclamaciones y que, pasado más de medio siglo, "un juicio válido resulta imposible", es decir, que los hechos estarían prescritos" (GRÜNENTHAL RECURRE..., 2013), a farmacêutica alemã recorreu e venceu a disputa judicial promovida pela AVITE, em fins de 2013. Esse cenário torna o caso ainda mais perverso, pois faz a vítima ser castigada duplamente: os afetados pela substância teratogênica acabam sendo vítimas da talidomida e vítimas da negação da fabricante da droga com relação a sua responsabilidade no caso. A afirmação de que "a ética não deveria prescrever" continua embasando a disputa atualmente.

\section{Considerações finais}

As breves reflexões feitas até aqui apontam para uma estratégia de luta por reparação impetrada pela AVITE por meio dos usos públicos do passado. Nela, diversas fontes são utilizadas para elaborar e manter presente uma memória acerca da tragédia da 
talidomida ocorrida na Espanha, de modo a informar o evento à sociedade e obter apoio em sua luta por reparação.

A análise desse estudo privilegiou o vídeo Mesa Redonda de AVITE, que consiste em uma entrevista realizada em 2016 com quatro vítimas do desastre da talidomida na Espanha e está disponível em vários canais de vídeo e redes sociais. Se partirmos do entendimento de que os meios de comunicação atuais são o principal lugar das experiências coletivas, tal como afirma Marialva Barbosa (2016), podemos ressaltar a relevância dos usos do passado feitos por eles. Desse modo, a utilização feita pela AVITE parece responder a uma emergência desses veículos como eventuais construtores de uma história de alcance público.

Contudo, devemos ter em vista a percepção de que, mesmo para uma demanda tão urgente, é essencial nos posicionarmos como historiadores, a quem cabe se distanciar metodologicamente do objeto na busca por entendê-lo. Mesmo no caso da talidomida, há uma seleção de fatos nos discursos apresentados, não a história toda. Por isso, precisamos, em estudo mais aprofundado, analisar quais histórias são evidenciadas e quais são silenciadas nesse complexo jogo de disputas. Não se deve ignorar, também, que mais lembranças não significam necessariamente mais conhecimento do passado.

Convém, desse modo, levar em conta o que nos escreve Pablo Pozzi (2016) acerca da seletividade da memória, a qual, segundo o autor, se constitui a partir das demandas do presente. Nesse sentido, a memória não é a verdade, e sim um reservatório coletivo de experiências em que as recordações se articulam de acordo com as necessidades atuais. Desse modo, mesmo que a memória possa dar um impulso moral à história e ser uma de suas fontes privilegiadas, não se deve admitir a relação inconteste entre o direito de lembrar e a verdade da lembrança. Para o uso de memórias dos afetados pela droga farmacêutica, vale a imposição da crítica ao testemunho, de modo que o relato oral seja confrontado com o que demonstram outras fontes, como buscamos fazer.

Pode-se aventar, nesse caso, que a investida da associação para reviver uma memória da tragédia por meio de produções audiovisuais que atingem relevante repercussão social condiz, por exemplo, com a perspectiva de que processos criminais 
podem não ser suficientes para sedimentar eventos hediondos na memória coletiva de uma nação, tal qual afirma Savelsberg (2007), ao discutir o papel de processos criminais na construção de memórias coletivas. Essa realidade provocaria a busca por maiores audiências, de formas alternativas, como no caso da produção e distribuição de vídeos online.

Vislumbrando elaborar uma memória negativa da empresa alemã no presente, a AVITE se utiliza da veiculação de relatos orais como o do programa analisado para atingir um público maior do que aquele que os tradicionais canais que noticiam essas questões atingem, ou mesmo, se interessam por atingir. Optar por narrar uma versão dos fatos por meio de ferramentas com maior impacto nos dias de hoje, tal qual a internet e os canais de vídeos online, permite à associação elaborar um conhecimento do desastre da talidomida junto ao público a fim de conseguir apoio ampliado às suas demandas.

O vídeo analisado representa, assim, uma modalidade audiovisual na qual se sobressai a preocupação com a exposição da realidade dos afetados pela droga como ação sensibilizadora, pela qual se evidenciam tensões políticas, jurídicas e sociais. Desse modo, a produção audiovisual procura colaborar com o conhecimento público sobre a difícil vida das vítimas e a falta de responsabilização da Grünenthal por parte da justiça espanhola e europeia, buscando angariar simpatizantes a sua causa e com isso, pressionar o Estado em busca por justiça.

Por outro lado, o modelo de publicização utilizado pela AVITE se encaixaria naquilo que Alexander Freund (2016, p. 160) intitula como "modismo das sociedades ocidentais", a contação pública de estórias autobiográficas. Esse autor alerta para a necessidade de historiadores não se enredarem na "cultura da terapia” (FREUND, 2016, p. 197) vigente. Para ele, a contação de histórias "mistura história e memória individual e, dessa forma, despolitiza o discurso público" (FREUND, 2016, p. 203), provocando um descolamento entre os problemas individuais e seu contexto histórico, com consequente invisibilização das responsabilidades das políticas públicas, por exemplo.

Observado por esse viés, o material aqui analisado demanda um cuidado adicional: a premissa de que relatos memoriais não podem ser interpretados como via de acesso a 
experiências autênticas. A partir das reflexões de Freund, finalizamos o texto reafirmando o cuidado em entender o material divulgado pela AVITE como fonte a ser historicizada e não, como uma história de vida legítima. Afinal, "nenhum testemunho fornece um acesso sem filtros do passado. Toda memória é filtrada pelo tempo e pela experiência vivida" (FREUND, 2016, p. 206).

\section{Referências}

BÉDARIDA, François. Tempo presente e presença da História. In: FERREIRA, M. de M., AMADO, J. (orgs). Usos \& abusos da história oral. Rio de Janeiro: FGV, p. 219-229, 1996.

BARBOSA, Marialva. Imprensa e História Pública. In: MAUAD, A. M., DE ALMEIDA, J. R, SANTHIAGO, R. História Pública no Brasil: sentidos e itinerários. São Paulo: Letra e Voz, 2016.

DE NAPOLI, Carlos. A fórmula da eterna juventude e outros experimentos nazistas. Rio de Janeiro: Civilização Brasileira, 2012.

DELACROIX, Christian. A história do tempo presente, uma história (realmente) como as outras? Tempo e Argumento, Florianópolis, v. 10, n. 23, p. 39-79, 2018.

DELGADO, Lucilia de Almeida Neves. História oral e narrativa: tempo, memória e identidades. História Oral, São Paulo, v. 6, p. 9-25, 2003.

FARGE, Arlette. Do sofrimento. In: Lugares para a História. Belo Horizonte: Ed. Autêntica, 2011.

FERREIRA, Marieta de Moraes. Historia oral: una brújula para los desafios de la historia. Historia, Antropología y Fuentes Orales, Barcelona, n. 28, p. 141-52, 2002.

FREUND, Alexander. Sob o encanto da contação de estórias? História oral numa era neoliberal. In: GONÇALVES, J. (Org.). História do tempo presente: oralidade - memória mídia. Itajaí: Casa Aberta, p. 159-223, 2016.

GRÜNENTHAL recurre la sentencia por las malformaciones de la talidomida. Jornal EL PAIS Online, Madrid, 20 dec. 2013. Disponível em: https://elpais.com/ sociedad/2013/12/20/actualidad/1387545219_166174.html. Acesso em: 17 dec. 2018.

HERSEY, John. Hiroshima. São Paulo: Companhia das Letras, 2002. 
HUYSSEN, Andreas. Culturas do passado-presente: modernismos, artes visuais, práticas da memória. Rio de Janeiro: Contraponto, 2014.

LEANDRO, José A.; LOPES, Bruna. Talidomida no Brasil: uma história de iatrogenia medicamentosa esquecida pelas ciências humanas e sociais. In: JORNADA DE SOCIOLOGIA DA SAÚDE, 7., 2013, Curitiba. Anais eletrônicos [...] Curitiba: UFPR, 2013. Disponível em: http://www.humanas.ufpr.br/portal/sociologiasaude/files/2013/12/ TALIDOMIDA-NO-BRASIL-IATROGENIA.pdf. Acesso em: 13 jan. 2013.

LEANDRO, José A.; SANTOS, Francieli. L. História da talidomida no Brasil a partir da mídia impressa (1959-1962). Saúde e Sociedade, São Paulo, v. 24, n. 3, p. 991-1005, 2015.

MARTíNÉZ-FRÍAS, Maria L. Talidomida: 50 anõs después. Med. Clin., Barcelona, v. 139, n. 1, p. 25-32, 2012.

MESA redonda de AVITE. Entrevistadora: Rosario Raro. Múrcia, 2016. 6 vídeos (58 min.). Publicado pelo canal AVITE TV. Disponível em:

https://www.youtube.com/watch?v=_70jVS6Nv5k . Acesso em: 06 ago. 2019.

MORO, Adriana; INVERNIZZI, Noela. A tragédia da talidomida: a luta pelos direitos das vítimas e por melhor regulação de medicamentos. História, Ciências, Saúde-Manguinhos, Rio de Janeiro, v. 24, n. 3, p. $603-622,2017$.

POZZI, Pablo A. Argentina 1976 - 1983: la oposición obrera a la ditadura em la memoria de cinco trabajadores. In: GONÇALVES, J. (Org.). História do Tempo Presente: oralidade memória - mídia. Itajaí, SC: Casa Aberta, p. 29- 58, 2016.

ROUSSO, Henry. A memória não é mais o que era. In: FERREIRA, M. de M., AMADO, J. (Orgs.). Usos \& abusos da História Oral. Rio de Janeiro: FGV, p. 93-102, 2006.

RINCÓN, Reyes; DE BENITO, Emilio. El Supremo rechaza indemnizar a los afectados de la talidomida. El país, Madrid, set. 2015. Disponível em:

<https://elpais.com/politica/2015/og/23/actualidad/1443009667_363778.html>. Acesso em: 20 abr. 2018.

SAVELSBERG, Joachim. Violações de direitos humanos, lei e memória coletiva. Tempo social, São Paulo, v. 19, n. 2, p. 13-37, Nov. 2007. Disponível em: http://www.scielo.br/ scielo.php?script=sci_arttext\&pid=S0103-20702007000200001\&lng=en\&nrm=iso. Acesso em: 20/12/2018

SELLIGMANN-SILVA, Márcio. O local do testemunho. Tempo e Argumento, Florianópolis, v. 2, n. 1, p. 3-20, jan.-jun. 2010. 
SELLIGMANN-SILVA, Márcio. Direito pós-fáustico: por um novo tribunal como espaço de rememoração e elaboração dos traumas sociais. In: ARAÚJO, Maria Paula; FICO, Carlos; GRIN, Monica (Orgs.). Violência na História: memória, trauma e reparação. Rio de Janeiro: Ponteio, 2012.

YO acuso - La verdad acerca de la talidomida. Jornal Hoja del Lunes, Barcelona, 4 jan. 1963.

Recebido em: 15/02/2019 Aprovado em: 03/07/2019

Universidade do Estado de Santa Catarina - UDESC Centro de Ciências Humanas e da Educação - FAED

Revista PerCursos Volume 20 - Número 42 - Ano 2019 revistapercursos@gmail.com 